\title{
Obstetric outcome in grand multipara - a Meghalaya experience
}

\author{
Indrani Roy, Ashish Burande, Richa Choubey \\ Correspondence: Dr Indrani Roy, Department of Obstetrics \& Gynaecology, Nazareth \\ Hospital, Laitumkhrah, Shillong - 793003, Meghalaya, India; \\ Email - indraniroydeb@gmail.com
}

Distributed under Attribution-NonCommercial-ShareAlike 4.0 International (CC BY-NC-SA 4.0)

\begin{abstract}
Objectives: This study was carried out to evaluate the obstetric and perinatal outcomes in grand multipara. Methods: A retrospective descriptive analytical study was carried out in the department of Obstetrics and Gynecology. All the case records of the grand multiparae (> gravida 5) admitted from $1^{\text {st }}$ February 2016 to $28^{\text {th }}$ February 2018 were observed for gravida, parity, age, religion, associated morbidities such as anaemia, pregnancy induced hypertension, gestational diabetes mellitus (GDM), obstetric complications such as post partum hemorrhage and rupture uterus, mode of delivery, neonatal outcome and maternal mortality. Results: Incidence of grand multiparity was $10.75 \%(571 / 5308)$. These 571 cases were from 3 groups: Group I - gravida 5 to $7(358=62.69 \%)$, Group II - gravida 8 to $10(158=27.67 \%)$ and group III - gravida $>10(55=9.63 \%)$. In group I and III all mothers belonged to Christian religion whilst in Group II, $0.35 \%$ were from other religions also. In this study the highest gravida was 18 gravida. The range of age was $18-48$ yrs (Mean age of 33.8 yrs). Incidence of significant anemia $(\mathrm{Hb}<8 \mathrm{~g} / \mathrm{dl})$, in the three groups were $7.82 \%, 8.86 \%$ and $14.54 \%$ respectively. Incidence of pregnancy induced hypertension was $6.98 \%, 9.49 \%$ and $10.90 \%$ in the three groups respectively. Incidents of GDM were $1.22 \%$ in total with $1.39 \%$ in Group I and $1.26 \%$ in Group II. Two hundred thirty three $(40.80 \%)$ deliveries were by lower segment caesarian section. Post partum hemorrhage occurred in $2.51 \%$, $3.16 \%$ and $9.09 \%$ in group I, II and III respectively. Three patients had rupture of uterus (two belonging to group II and one in group I). There was no maternal mortality. Only 35(6.12\%) deliveries resulted in perinatal deaths of which $4.37 \%$ (25) were still births. There were no congenital anomalies in the babies. Conclusion: Owing to unique social and religious influences in the hill state of Meghalaya with predominantly tribal population, there is high incidence of grand multiparity. This study concludes that there is no significant increase in incidence of maternal morbidities and mortality with increasing parity in the women of Meghalaya.
\end{abstract}

Keywords: Grand multipara, pregnancy induced hypertension, GDM.

The International Federation of Gynecology and undergoing their tenth (or more) delivery are considered Obstetrics (1993) defines grandmultiparity as delivery of to be great - grandmultiparae. In his 1934 article, entitled the fifth to ninth infant, whereas women who are 'The dangerous multiparae', Bethel Solomons ${ }^{1}$ wrote:

Received: $26^{\text {th }}$ May 2018. Accepted: $16^{\text {th }}$ October 2018.

Roy I, Burande A, Choubey R. Obstetric outcome in grand multipara - a Meghalaya experience. The New Indian Journal of OBGYN. 2019; 5(2): 103-6 
" my main object is to remove if possible once and for all, the idea that a primigravida means a difficult labour but a multiparae means a easy one. It is altogether a mistake to suppose that in childbearing, practice makes perfect'. Solomons' concern for the multiparae was prompted by a study at the time from the Department of Health for Scotland which showed the maternal mortality rate associated with multiparity increasing "steadily and speedily" from the fifth pregnancy until women bearing their tenth child or more had a mortality rate five times as high as all women bearing children. ${ }^{1}$

Grandmultiparity is very commonly linked to certain complications during labour like malpresentation, labour dysfunction, abruption placentae, haemorrhage in the post partum period, and rupture uterus ${ }^{2}$. Reported studies from different parts of the world include various studies in the US, Hong Kong, mostly in the low socioeconomic status group of population. There is contradictory data in the literature about the risks associated with grandmultiparity. Different studies quote different definition for grandmultiparity whereas Toohey et al ${ }^{3}$ used the definition of parity greater or equal to five.

The main tribes in Meghalaya are the Jaintias, the Khasis and the Garos. One of the unique features of the state is that a majority of the tribal population in Meghalaya follows a matrilineal system where lineage and inheritance are traced through women. The Khasi and Jaintia tribesmen follow the traditional matrilineal norm, wherein the youngest daughter inherits all the property and acts as the caretaker of aged parents and any unmarried siblings. The tribal people of Meghalaya are therefore a part of what may be the world's largest surviving matrilineal culture. According to National Family Health Survey, Meghalaya is the state where parents have shown the least interest to have a male child- $-73 \%$ less than the national average. Christianity is practiced by the majority (70.3\%) in Meghalaya. The aim of this study is to see the obstetric and perinatal outcome in grand multiparae delivering in the Department of obstetrics and gynaecology.

\section{Materials and Methods}

This retrospective study was carried out in the department of obstetrics and gynaecology of Nazareth hospital, Shillong, Meghalaya from $1^{\text {st }}$ February 2016 to $28^{\text {th }}$ February 2018. Nazareth hospital is a 350 bedded multi specialty, catholic missionary hospital located in Shillong, the capital of Meghalaya. The city is the headquarters of East Khasi hills district and the hospital caters to patients from two nearby districts also. There is a 70 bedded obstetrics unit. The hospital caters primarily to the rural populace and also urban patients of Meghalaya. The delivery rate in this hospital is $2000-2500$ deliveries per year. Subsidized outdoor and indoor services are available round the clock. The patients attending the obstetrics department belong mainly to the lower and lower middle socioeconomic groups. The patients belong primarily to the indigenous tribes of Meghalaya (Khasi and Jaintia) and birth control measures are rarely practiced. Hospital records of all deliveries in the department of obstetrics and gynecology during the period of study were screened to detect the grand multiparae (gravida 5 and above). Thereafter their files were examined to record the outcome observations. Demographic data was recorded. Data were shown in table with number and percentage.

The following outcomes were recorded:

1. Anemia: Hemoglobin level less than $8 \mathrm{gm} / \mathrm{dl}$

2. Gestational hypertension: Blood pressure $\geq$ 140/90 mm Hg

3. Gestational diabetes mellitus: Glucose Challenge test: $>140 \mathrm{mg} / \mathrm{dl}$

4. Post partum hemorrhage

5. Other obstetric complications

6. Mode of delivery

7. Maternal mortality

8. Intrauterine death

9. Neonatal outcomes: prematurity, small for gestational age, congenital anomalies, neonatal death

The grand multiparae were divided on the basis of gravida into three groups:

Group I: Gravida $5-7$

Group II:Gravida $8-10$

Group III: Gravida $>10$

\section{Results}

Total number of deliveries during the study period was 5308 , out of which 571 (10.75\%) were grand multipara. The outcomes are summarized in Table 1. The highest gravida in the present study was $\mathrm{G}_{18}, \mathrm{P}_{13+4}$; she developed gestational hypertension in the third trimester of 
pregnancy. She delivered a healthy baby by caesarean section with no post partum hemorrhage. Three patients underwent bilateral uterine artery ligation following LSCS due to atonic postpartum hemorrhage to control the anemia, preterm delivery, and meconium-stained amniotic fluid increased with higher parity, whereas the rate of excessive weight gain and cesarean delivery decreased. They also found that the incidence of postpartum

Table 1: Demographic Data

\begin{tabular}{lllll}
\hline Variables & Group I & Group II & Group III & Total \\
\hline $\begin{array}{l}\text { Number of patients } \\
\text { (grand multiparae) }\end{array}$ & $358(62.69 \%)$ & $158(27.67 \%)$ & $55(9.63 \%)$ & 571 \\
Age $>38$ yrs & $48(13.40 \%)$ & $46(29.11 \%)$ & $30(54.54 \%)$ & $124(21.71 \%)$ \\
Religion & Christian: $358(100 \%)$ & Christian: $156(98.7 \%)$ & Christian:55(100\%) & Christian:569(99.64\%) \\
Anemia & $28(7.82 \%)$ & Others: $2(0.35 \%)$ & & Others:2(0.35\%) \\
Gestational hypertension & $25(6.98 \%)$ & $14(8.86 \%)$ & $8(14.54 \%)$ & $50(8.75 \%)$ \\
Gestational diabetes & $5(1.39 \%)$ & $15(9.49 \%)$ & $6(10.90 \%)$ & $46(8.05 \%)$ \\
Post partum hemorrhage & $9(2.51 \%)$ & $2(1.26 \%)$ & 0 & $7(1.22 \%)$ \\
Rupture uterus & $1(0.27 \%)$ & $5(3.16 \%)$ & $5(9.09 \%)$ & $19(3.32 \%)$ \\
Caesarean sections & $132(36.87 \%)$ & $2(1.26 \%)$ & 0 & $3(0.52 \%)$ \\
Maternal mortality & 0 & $81(51.26 \%)$ & $20(36.36 \%)$ & $233(40.80 \%)$ \\
Still births & $15(4.18 \%)$ & 0 & 0 & 0 \\
Neonatal deaths & $5(1.39 \%)$ & $9(5.69 \%)$ & $1(1.81 \%)$ & $25(4.37 \%)$ \\
Congenital anomalies & 0 & $3(1.89 \%)$ & $2(3.63 \%)$ & $10(1.75 \%)$ \\
Prematurity & $15(4.18 \%)$ & 0 & 0 & 0 \\
Small for dates & $31(8.65 \%)$ & $7(4.43 \%)$ & $3(5.45 \%)$ & $25(4.37 \%)$ \\
\hline
\end{tabular}

bleeding. One patient underwent obstetric hysterectomy for rupture uterus.

\section{Discussion}

Incidence of grand multipara has been gradually declining all over the world over a couple of decades due to acceptance of small family norm but it still constitutes about $10 \%$ of all hospital admissions and accounts for $3 \%$ of maternal deaths in developing countries.

Matusiak R (2002) et $\mathrm{al}^{4}$ in a Polish study found that grand multiparae experienced preterm deliveries, gained less weight during pregnancy and amniorrhexis took place in a more advanced 1st stage of labor. Perineal ruptures and episiotomies were significantly less frequent in the study group. But they concluded that grand multiparity seems not to be an independent risk factor of obstetrical complications and should not be considered dangerous in centers with well organized modern perinatal care.

In another study by Babinszki A et al (1998) from New York, USA ${ }^{5}$ found that the incidence of malpresentation at the time of delivery, maternal obesity, hemorrhage, preeclampsia, placenta previa, macrosomia, postdate pregnancy, and low Apgar scores was significantly higher in grand multiparae than in multiparae, whereas the proportion of induction, forceps delivery, and total labor complications was significantly lower than in the multiparous group $(\mathrm{P}<.05)$. Similar frequency of maternal diabetes, infection, uterine wall scar rupture, variations in fetal heart rate, fetal death, and neonatal mortality was found in both the groups. Their study concluded that both high-parity groups have their own risk factors, but the rate of some complications decreases with higher parity. In addition, perinatal mortality remains low in these patients, and therefore, under satisfactory socioeconomic and health care conditions, high parity should not be considered dangerous. Several other studies by Humphrey MD (Australia 2004), ${ }^{6}$ Hinkula $\mathrm{M}$ et al (Finland 2001), ${ }^{7}$ Julianne S Toohey (1994), ${ }^{3}$ Jun Bai et al (Australia 2001), ${ }^{8}$ Seidman D S et al ${ }^{9}$ (Israel) from different parts of the world with women from different socioeconomic 
The New Indian Journal of OBGYN. 2019 (January-June); 5(2)

groups and varying health facilities all concluded that grand multiparity does not carry an increased risk of perinatal morbidity or mortality. In another study by Smriti Agarwal et al from Lucknow (2007) ${ }^{10}$, compared 92 grand multiparae with a control group and found that there was increased incidence of anemia, placenta previa, rupture uterus, premature labor and death in the grand multiparae. Their study concluded that increased parity increased mortality and morbidity.

The present study found the incidence of grand multipara to be $10.75 \%$ of all hospital deliveries during the study period ( 25 months). Of the grand multiparae, 99.64\% belonged to Christian religion. Incidence of anemia was $8.75 \%$, gestational hypertension was $8.05 \%$, gestational diabetes being $1.22 \%$, ceasarean sections were $40.80 \%$ (commonest indications were obstructed labor and fetal distress), post partum hemorrhage being 3.32\%, rupture uterus was $0.52 \% . \quad 0.17 \%$ underwent hysterectomy, due to rupture uterus. In the present study, perinatal mortality was $1.75 \%$, congenital anomalies was $0 \%$, prematurity $4.37 \%$ and small for dates were $9.63 \%$. There was no maternal mortality in this study showing that with fair obstetric and perinatal care, incidence of maternal and perinatal mortality in grand multiparae was not significantly increased.

\section{Conclusion}

Owing to the unique social and religious influences in the hill state of Meghalaya with predominantly tribal population following matrilineal system, there is a high incidence of grand multiparity. With regular antenatal care, identification of high risk factors, active management of $3^{\text {rd }}$ stage of labor; the incidence of maternal morbidity and mortality can be reduced even in grand multipara. This study concludes that there is no significant increase in incidence of maternal morbidity and mortality with increased parity in the women of Meghalaya.

\section{Conflict of interest: None. Disclaimer: Nil.}

\section{References}

1.Solomons B. The dangerous multipara. Lancet 1934; 2: 811

2.Bugg GJ, Atwal GS, Maresh M. Grandmultiparae in a modern setting. BJOG. March 2002; 109(3): 249 -53.

3.Toohey JS, Keegan KA, Morgan MA, Francis J, Task S, de Veciana M. The dangerous multipara: fact or fiction? Am J Obstet Gynecol. 1995;172(2pt1): $683-6$.

4.Matusiak R, Szymusik I, Kosińska-Kaczyńska K, Borowska A, Myszewska A, Morawski Z, Wielgoś M, Przyboś A. Is grand multiparity an obstetrical risk factor? Ginekologia Polska. 2006; 77(12): 937 - 44

5.Babinski A, Kerenyi T, Torok O, Grazi V, Lapinski RH, Berkowitz RL. Perinatal outcome in grand and great-grand multiparity: effects of parity on obstetric risk factors. Am J Obstet Gynecol. 1999; 181(3): 669- 74.

6.Humphrey MD. Is grand multiparity an independent predictor of pregnancy risk? A retrospective observational study. Med J Aust. 2004;180(4):196-7

7.Hinkula M, Kauppila A, Näyhä S, Pukkala E. Causespecific mortality of grand multiparous women in Finland. Am J Epidemiology. 2006; 163(4): 367 - 7

8.Bai J, Wong FW, Bauman A, Mohsin M. Parity and pregnancy outcomes. Am J Obstet Gynecol. 2002; 186(2): 274-8

9. Seidman DS, Armor Y, Roff D, Stevenson DK, Gale R. Grand multiparity: An obstetric or neonatal risk factor? Am J Obstet Gynecol. 1988; 158(5):1034 - 9.

10.Agrawal S, Das V, Agarwal A, Pandey A, Jain V. To evaluate obstetric outcome in grandmultipara women; Proceedings of 52nd AICOG conference. Jaipur; 2009.

\section{Indrani Roy ${ }^{1}$, Ashish Burande ${ }^{2}$, Richa Choubey ${ }^{3}$} ${ }^{1}$ Senior Consultant; ${ }^{2}$ DNB Trainee; ${ }^{3}$ DNB Trainee, Department of Obstetrics and Gynaecology, Nazareth Hospital, Shillong, Meghalaya, India. 